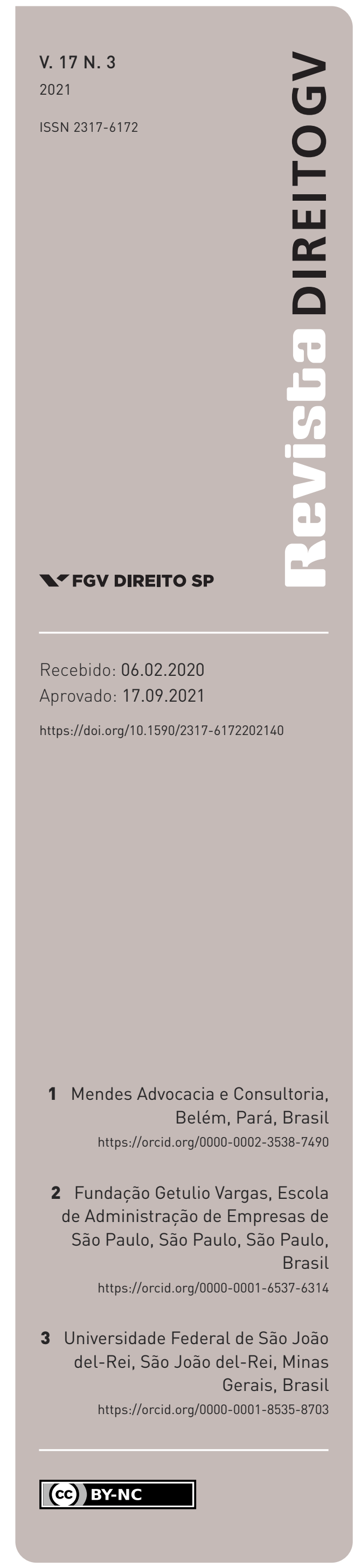

\section{Liderança relacional e modernidade organizacional em firmas de advocacia de Belém do Pará}

RELATIONAL LEADERSHIP AND ORGANIZATIONAL MODERNITY IN BELÉM DO PARÁ LAW FIRMS

\author{
Lucca Darwich Mendes', Anderson de Souza Sant'Anna ${ }^{2}$ \\ e Daniela Martins Diniz ${ }^{3}$
}

\section{Resumo}

Este artigo tem como foco apresentar resultados de estudo destinado a investigar relações entre os constructos modernidade organizacional e liderança relacional em organizações profissionais, mais especificamente em escritórios de advocacia. As transformações que o setor tem vivenciado, particularmente em face dos movimentos em torno da chamada "Quarta Revolução Industrial", têm imprimido alterações significativas não somente no escopo de atuação, produtos e serviços, como também nos perfis, processos e modos de entrega, requeridos ao exercício profissional da advocacia. Por conseguinte, suscitam estilos de liderança mais flexíveis, descentralizados e distribuídos, mais afins aos pressupostos da chamada liderança relacional. Quanto ao método, foi desenvolvida pesquisa de abordagem quantitativa envolvendo a aplicação de survey junto a advogados dos dez maiores escritórios de advocacia localizados na cidade de Belém (PA). Os resultados indicam escores elevados de modernidade cultural, seguida de modernidade administrativa e de práticas de gestão de pessoas e, por fim, de modernidade política. Registra-se também presença significativa dos fatores de liderança relacional investigados, assim como correlação positiva e significativa entre modernidade organizacional e liderança relacional. Uma importante contribuição do estudo diz respeito à superação de lacuna na literatura quanto a medidas e pesquisas empíricas direcionadas à mensuração da liderança relacional em escritórios de advocacia.

\section{Palavras-chave}

Liderança relacional; modernidade organizacional; firmas de advocacia.

\begin{abstract}
This paper aims to present the results of a study aimed at investigating the relationship between the constructs Organizational Modernity and Relational Leadership in professional organizations, more specifically in law firms. The transformations that the sector has been undergoing, particularly in light of the movements surrounding the so-called "Fourth Industrial Revolution", have brought about significant changes, not only in the scope of practice, products, and services, but also in the profiles, processes, and delivery modes required for the professional practice of law. Consequently, it gives rise to more flexible, decentralized, and distributed leadership styles, more in line with the assumptions of the so-called relational leadership. As for the method, a research with a quantitative approach was developed, involving the application of a survey with lawyers from the ten largest law firms located in the city of Belém (PA). The results indicate high scores for cultural modernity, followed by administrative modernity and people management practices, and finally, political modernity. The results also show a significant presence of the relational leadership factors investigated, as well as a positive and significant correlation between organizational modernity and relational leadership.
\end{abstract}


LIDERANÇA RELACIONAL E MODERNIDADE ORGANIZACIONAL EM FIRMAS DE ADVOCACIA DE BELÉM DO PARÁ : $\mathbf{2}$

An important contribution of this study was to overcome the gap in the literature regarding measures and empirical research aimed at measuring relational leadership in law firms.

Keywords

Relational leadership; organizational modernity; law firms.

\section{INTRODUÇÃO}

Com acentuado vínculo à tradição, as trajetórias ocupacionais dos advogados têm na reputação e no conhecimento técnico-jurídico fatores historicamente distintivos (SELEM, 2009). Recentes transformações em torno do que se denomina "Quarta Revolução Industrial" (SCHWAB, 2016) - incluindo a introdução de tecnologias digitais e de inteligência artificial (KAPLAN, 2017; SCHWAB, 2016; ROSS, 2016; MORGAN, 2014; BRYNJOLFSSON e MCAFEE, 2011) - têm, no entanto, suscitado alterações significativas tanto no escopo quanto em competências requeridas aos profissionais da advocacia, assim como nas formas de sua organização e representação institucional (SUSSKIND e SUSSKIND, 2017; FREY e OSBORNE, 2010; SUSSKIND, 2008).

Além da demanda por novos atributos individuais, a economia digital, a mundialização da economia e formas outras de coordenação e integração inter e interorganizacionais têm implicado a abertura de novos mercados, assim como diferenciados arranjos e configurações de exercício profissional, incluindo modelos em plataformas, redes, coletivos e cooperativas (LEE, 2016; ISMAIL, 2014; ANDERSON, 2012; CHRISTENSEN, 2006).

Tais configurações refletem funções e processos que extrapolam o âmbito do exercício convencional das funções do Direito, incorporando, além de conhecimentos, habilidades e atitudes jurídicas, competências gerenciais relativas a gestão de contratos, recrutamento, seleção e avaliação de desempenho de sócios, associados e colaboradores. Além disso, somam-se atribuições mais estratégicas, como formação de alianças e parcerias estratégicas, coordenação de processos de fusões e aquisições, planejamento e implementação de planos estratégicos de negócios, entre outras de mesma natureza (GONÇALVES, 2008).

Conforme destaca Gonçalves (2012), o foco do advogado alinha-se cada vez mais à lógica de mercado e de resultados, típica do mundo empresarial. Em linhas gerais, não mais se trata de equacionar questões jurídicas, mas, igualmente, de as antecipar e mediar. E mais: é preciso identificar oportunidades para seus clientes e prospects, agregando valores que outros tipos de inteligência - como a artificial - não possam transacionar (SUSSKIND e SUSSKIND, 2017; FREY e OSBORNE, 2010; SUSSKIND, 2008). 
Como resultado, assiste-se à busca por novos "modelos de negócios" e estruturas organizacionais centrados na prestação de serviços com maior grau de profissionalização e aderência a parâmetros contemporâneos de gestão, inserindo-se a busca por melhoria contínua dos processos internos e da prestação de serviços; assim como à atração e retenção de parceiros, associados, talentos e novos clientes, por meio de políticas e práticas que fomentem a criação e a inovação (SUSSKIND e SUSSKIND, 2017; SELEM, 2009; SUSSKIND, 2008).

Concomitantemente, estudos internacionais sobre o processo de transformação em curso em escritórios e firmas globais de advocacia apontam a liderança como fator crítico ao acompanhamento das tendências em curso (SUSSKIND e SUSSKIND, 2017; SUSSKIND, 2008). Para além dos estilos de liderança assentados na tradição e no conhecimento intrínseco do saber jurídico, a noção de liderança relacional (UHL-BIEN, 2006) apresenta-se aderente à difusão dos novos modelos de negócios e gestão, marcados pela demanda por configurações e arquiteturas organizacionais mais horizontalizadas, orgânicas e em rede, capazes de dar respostas mais efetivas à volatilidade, incerteza e fluidez dos ambientes contemporâneos de negócios. Isso ocorre na medida em que se propõe superar abordagens de liderança muito centradas no indivíduo, em seus traços e em suas competências, desconsiderando conexões entre seus profissionais e destes com as organizações (UHL-BIEN e ARENA, 2018; QUICK, 2014; CUNLIFFE e ERIKSEN, 2011).

Nesse sentido, ao extrapolar a compreensão da liderança alicerçada em características pessoais ou de sua manifestação em aspectos comportamentais evidenciados no ambiente organizacional, de forma não integrada, a liderança relacional, ao privilegiar a dimensão contextual e indo além da análise da díade líder-liderado, propõe superar importante lacuna dos Leadership Studies, trazendo à tona perspectivas de análise mais sistêmicas e multidimensionais (UHL-BIEN e ARENA, 2018; QUICK, 2014; CUNLIFFE e ERIKSEN, 2011).

Nesse contexto, a necessidade de repensar o exercício da liderança expande-se também em face da expansão de setores não industriais, por meio dos chamados serviços profissionais (professional services), aos quais se integram instituições de saúde, educacionais, firmas de consultoria e de serviços jurídicos (GREENWOOD e LACHMAN, 1996). Não obstante, a gestão de tais organizações depara-se com desafios históricos, como a reduzida tônica de seus membros no desenvolvimento e exercício de competências associadas à gestão (BORCK, 2008).

Desse contexto advém a proposta central da pesquisa que subsidia os achados compartilhados neste artigo. Afinal, será essa a realidade também vivenciada por escritórios de advocacia no Brasil? Em outros termos, em que medida atributos associados ao estilo de liderança relacional correlacionam-se a políticas e práticas de gestão vinculadas ao preconizado por modelos contemporâneos de negócios, típicos da modernidade tardia na transição para a Quarta Revolução Industrial? (UHL-BIEN e ARENA, 2018; SCHWAB, 2016; EBOLI, 1996; TOURAINE, 1994). Tendo por base tal questão, seu foco consiste em analisar relações entre fatores de modernidade organizacional e estilos de liderança vigentes em escritórios de 
advocacia, buscando melhor compreender em que medida o exercício de estilos mais contemporâneos de influência - centrados na perspectiva relacional - relacionam-se às demandas por maior profissionalização de políticas e práticas de gestão de organizações do tipo profissional (MINTZBERG, 2003).

No que concerne à sua relevância, espera-se que os achados aportem elementos que auxiliem na superação de lacunas acerca das implicações das transformações em curso (SCHWAB, 2016) e dos seus impactos nas organizações do tipo profissional, assim como na mensuração de aspectos dos estudos sob a perspectiva relacional - incluindo a liderança. Salientam-se, ademais, lacunas quanto a estudos empíricos sobre a liderança relacional, assim como de propostas de mensuração, vácuo que demanda a realização de investigações a partir da aplicação de estudos em organizações concretas, como a proposta para fins deste artigo.

\section{REFERENCIAL TEÓRICO}

\section{I. A LIDERANÇA SOB O ENFOQUE RELACIONAL}

Nos tempos atuais, a liderança constitui um dos constructos do comportamento organizacional sobre o qual mais se produzem artigos e livros. Desse universo, algumas abordagens têm, contemporaneamente, recebido significativa atenção, em nível tanto acadêmico quanto empresarial, destacando-se as abordagens da liderança transformacional (BURNS, 1978), liderança multidimensional e multinível (YAMMARINO, DANSEREAU e KENNEDY, 2001), assim como, mais recentemente, as concepções em torno da liderança relacional (UHLBIEN, 2006; DAY e HARRISON, 2007).

Em linhas gerais, a abordagem relacional baseia-se na premissa de que a liderança é resultante da interseção entre diversos níveis, englobando o individual, o organizacional e o societal. Diferentemente das demais abordagens, a perspectiva da liderança relacional enfatiza, portanto, as interações subjacentes às dinâmicas de influência em diversos níveis (CLEARY et al., 2018; MIRANDA, 2015; UHL-BIEN, 2006). Logo, a problemática central que orienta suas investigações são os processos relacionais nos quais a liderança emerge e é exercida.

A liderança relacional centra-se nas relações e investiga a forma como a liderança é ativada, construída, exercida e reconfigurada, afastando-a de correntes fundamentadas exclusivamente no indivíduo e/ou em seus seguidores. Assim, vai além de considerações situacionais e contingenciais e propõe uma análise integrada e sistêmica dos múltiplos níveis e das dimensões intervenientes na dinâmica organizacional, cujo exame ainda se encontra amplamente pautado no âmbito comportamental, mesmo em abordagens como a liderança situacional, contingencial, transformacional, multidimensional e multinível. Logo, a abordagem relacional aproxima-se da natureza das organizações profissionais quando busca 
superar o vínculo da liderança de posições e estruturas mais hierarquizadas, defendendo o debate das relações humanas e do ambiente em que se processam (QUICK, 2014), sendo marcante a valorização do contexto e de ambiências organizacionais aderentes à efetiva dinâmica da liderança.

Para Uhl-Bien (2006), precursora dos estudos sobre o tema, a liderança relacional é conceituada como um processo de influência social resultante dos vínculos entre o indivíduo, a organização e o ambiente no qual se insere. Segundo ela, embora variadas definições de liderança relacional possam ser encontradas na literatura, duas expressões são comumente citadas: influência e mudança.

Day e Harrison (2007) conceituam liderança relacional como uma propriedade compartilhada de um sistema social marcado por inter-relações entre pessoas, times, empresas e sociedade. Está relacionada, portanto, à instância da coletividade, e envolve a construção de entendimentos compartilhados entre os indivíduos. O desenvolvimento de líderes deve incorporar ações baseadas no coletivo, superando uma ênfase no líder individual e favorecendo a criação e o fortalecimento do capital social (MIRANDA, 2015).

Cunliffe e Eriksen (2011), por sua vez, propõem três enfoques direcionados à investigação da liderança relacional: rede-ator, construção social, pós-heroica. O primeiro baseia-se na noção de que o líder é um dos diversos elementos no processo de construção da rede relacional. A linha da liderança como construção social concentra-se na investigação de microprocessos em que os líderes constroem socialmente as normas, os valores e as estratégias das organizações nas quais estão imersos. Por fim, a liderança pós-heroica parte da premissa de que a liderança é exercida em empresas não hierárquicas e fundamentadas na colaboração, no trabalho em equipe e na confiança (MIRANDA, 2015). Posteriormente, Uhl-Bien e Arena (2018) propõe tipologia de enfoques da liderança relacional baseada em dois grandes grupos: as abordagens, que mesmo ao incorporarem perspectivas que relacionam múltiplos fatores contextuais, ainda dispõem como pivô central a pessoa do líder (Teorias da Entidade) e as abordagens relacionais propriamente ditas, em que as diferentes dimensões em análise - societais, organizacionais, pessoais - são consideradas de modo mais sistêmico e inter-relacionado. Esse último tipo é adotado para fins da pesquisa que subsidia os resultados deste estudo.

No contexto brasileiro, Miranda (2015, p. 36) entende que "a liderança relacional focaliza a natureza, distribuição e qualidade dos laços sociais que se estabelecem na dinâmica que leva o indivíduo a estabelecer uma relação de influência e mudança. Nessa direção, é fundamental o desenvolvimento de vínculos sociais efetivos, sejam eles fracos, sejam fortes. Os autores propõem uma relação de indicadores para mensuração da liderança relacional que serviram de base para a elaboração da escala de liderança, considerada para fins deste estudo (Quadro 1). 
LIDERANÇA RELACIONAL E MODERNIDADE ORGANIZACIONAL EM FIRMAS DE ADVOCACIA DE BELÉM DO PARÁ : 6

QUADRO 1 - INDICADORES DE LIDERANÇA RELACIONAL

\section{DIMENSÕES INDICADORES}

SOCIETAL

COERÊNCIA ENTRE VALORES ORGANIZACIONAIS PRECONIZADOS PELAS LIDERANÇAS E VALORES SOCIETAIS.

COERÊNCIA ENTRE VALORES ORGANIZACIONAIS E POLÍTICAS DE GESTÃO ADOTADAS.

COERÊNCIA ENTRE VALORES ORGANIZACIONAIS E PRÁTICAS DE GESTÃO IMPLEMENTADAS.

COERÊNCIA ENTRE VALORES ORGANIZACIONAIS E COMPORTAMENTO DAS LIDERANÇAS.

COMPORTAMENTO DAS LIDERANÇAS DIANTE DE DIFERENTES STAKEHOLDERS.

REPUTAÇÃO DAS LIDERANÇAS EM MEIO AOS PÚBLICOS INTERNO E EXTERNO.

COMPORTAMENTO DAS LIDERANÇAS DIANTE DE MUDANÇAS NO MACROAMBIENTE DE NEGÓCIOS.

ATENÇÃO DAS LIDERANÇAS QUANTO ÀS AGENDAS E QUESTÕES RELEVANTES AOS DIFERENTES PÚBLICOS DA ORGANIZAC̣ÃO.

COMPORTAMENTO ÉTICO DAS LIDERANÇAS.

ORGANIZACIONAL HÁ GENUÍNA PREOCUPAC̦ÃO DAS LIDERANÇAS COM AS PESSOAS DA ORGANIZAÇÃO.

HÁ ABERTURA DAS LIDERANÇAS PARA OUVIR AS PESSOAS.

OS RESULTADOS FINANCEIROS SÃO O PRINCIPAL FOCO DAS AC̣ÕES DAS LIDERANC̣AS DA ORGANIZAC̣ÃO.

AS LIDERANÇAS DA ORGANIZAÇÃO INSPIRAM AS PESSOAS À INOVAÇÃO.

AS LIDERANÇAS DA ORGANIZAC̣ÃO INSPIRAM AS PESSOAS AO EXERCÍCIO DA CIDADANIA.

AS LIDERANÇAS DA ORGANIZAC̣ÃO SÃO ORIENTADAS A RESULTADOS.

AS LIDERANÇAS DA ORGANIZAC̣ÃO SÃO ORIENTADAS AO CONTROLE.

AS LIDERANÇAS ENVOLVEM AS PESSOAS NAS PRINCIPAIS DECISÕES.

TENHO CONFIANC̣A NAS LIDERANÇAS DA ORGANIZAÇÃO.

PERCEBO UMA GRANDE DISTÂNCIA ENTRE MIM E AS LIDERANÇAS DA ORGANIZAC̣ÃO.

NÃO CONCORDO COM A FORMA COMO A LIDERANC̦A É EXERCIDA NA ORGANIZAC̦ÃO.

O ESTILO DAS LIDERANÇAS DA ORGANIZAÇÃO É, NO GERAL, CONSERVADOR.

O ESTILO DAS LIDERANÇAS DA ORGANIZAÇÃO É, NO GERAL, ARROJADO E INOVADOR.

O ESTILO DAS LIDERANÇAS DA ORGANIZAÇÃO É, NO GERAL, PARTICIPATIVO.

O ESTILO DAS LIDERANÇAS DA ORGANIZAÇÃO É, NO GERAL, BUROCRÁTICO.

A PRINCIPAL MARCA DAS LIDERANÇAS DA ORGANIZAC̣ÃO É O CARISMA.

A PRINCIPAL MARCA DAS LIDERANÇAS É O CONHECIMENTO DA GESTÃO DO NEGÓCIO.

A PRINCIPAL MARCA DAS LIDERANÇAS DA ORGANIZAÇÃO É O CONHECIMENTO NO CAMPO JURÍDICO.

A PRINCIPAL MARCA DAS LIDERANC̦AS SÃO SUAS RELAC̣ÕES COM O MUNDO EXTERNO.

(continua) 
LIDERANÇA RELACIONAL E MODERNIDADE ORGANIZACIONAL EM FIRMAS DE ADVOCACIA DE BELÉM DO PARÁ : 7

SINTO-ME CONTROLADO PELAS LIDERANÇAS DA ORGANIZAÇÃO.

AS LIDERANC̦AS SÃO CONSIDERADAS “LIIDERES” POR SEREM OS DONOS DO NEGÓCIO.

O LÍDER DA ORGANIZAÇÃO É CONSIDERADO COMO TAL POR SER O FUNDADOR.

NÃO CONSIDERO LIDERANÇA UM ELEMENTO IMPORTANTE NA DINÂMICA DA ORGANIZAÇÃO.

AS RELAC̣ÕES NA ORGANIZAC̣ÃO SÃO HORIZONTALIZADAS.

INDIVIDUAL

CONSIDERO LIDERANÇA UMA COMPETÊNCIA IMPORTANTE AO EXERCÍCIO DA MINHA PROFISSÃO.

PARA MIM, “LIDERAR” É SINÔNIMO DE “MANDAR”.

LIDERANÇA É UM TEMA PRIORITÁRIO NO DESENVOLVIMENTO DE MINHAS COMPETÊNCIAS.

LIDERAR É UMA COMPETÊNCIA PARA PESSOAS DIFERENCIADAS.

SINTO-ME UMA LIDERANÇA NA ORGANIZAÇÃO.

PREFIRO “COMANDAR" A “OBEDECER".

LIDERANC̦A, PARA MIM, DERIVA DE CONHECIMENTO TÉCNICO.

CONSIDERO SER POSSÍVEL DESENVOLVER A CAPACIDADE DE LIDERANÇA.

PARA MIM, LIDERANÇA É INATA.

SINTO FACILIDADE EM INFLUENCIAR PESSOAS.

PARA MIM, LIDERANÇA É UM TRAÇO PESSOAL.

NÃO VEJO COMO DESENVOLVER LIDERANÇA: “OU SE É LíDER OU NÃO SE É”.

LIDERANÇA É ALGO QUE PODE SER CONSTRUIIDO NO DIA A DIA DAS RELAÇÕES.

LIDERANÇA ESTÁ DIRETAMENTE ASSOCIADA À POSIC̣ÃO HIERÁRQUICA OCUPADA PELO INDIVÍDUO.

GOSTO DE TOMAR DECISÕES.

LIDERAR É CONTROLAR.

GOSTO DE EXERCER O PODER.

SINTO-ME MAIS ORIENTADO A TAREFAS QUE A PESSOAS.

EM GRUPOS, SEMPRE TOMO AS INICIATIVAS.

Fonte: Sant'Anna, Nelson e Carvalho Neto (2015).

\section{I.2. MODERNIDADE DE POLÍTICAS E PRÁTICAS DE GESTÃo}

Historicamente, as origens da noção de modernidade podem ser localizadas na transição entre o período medieval e o moderno, induzida pela introdução de novas tecnologias, da razão científica e das ideias de progresso e democracia (ZAJDSZNAJDER, 1993). Para o pensador francês Alain Touraine, a ideia de modernidade origina-se de duas abordagens, o racionalismo 
greco-romano e a concepção cristã de alma, baseada na noção de sujeito. Touraine (1994) destaca que a modernidade passou por uma crise justamente por ter ignorado o sujeito como parte do processo e restringido sua definição sob a ótica da eficácia da racionalidade instrumental, ressaltando que o caminho para a superação de problemas sociais está no resgate do homem e em seu redirecionamento para o centro da sociedade, que assim se estabeleceria uma nova modernidade.

Ainda na perspectiva desse autor, a modernidade, ao colocar o homem como centro do universo, pressupõe sua análise sob várias dimensões, destacando a tecnológica (combinando subjetivação e racionalização), a social (entendendo ser fundamental o movimento social para a subjetivação), a política (considerando a democracia regime para que o homem possa se expressar politicamente) e a cultural (considerando que os valores de liberdade e eficácia se encontram na sua origem).

No âmbito organizacional, a ideia de modernidade tem sido atrelada à necessidade de as organizações se prepararem para as mudanças em curso no mundo corporativo, sob os pilares da ciência administrativa como premissa para a competição no mercado, por meio da utilização de estratégias, políticas e práticas de gestão (management) que estimulem o comportamento eficaz. O entendimento de Eboli (1996) é pela necessidade de rompimento com práticas prevalentes de gestão, em razão de essas se mostrarem insuficientes para ao ambiente contemporâneo de negócios, fazendo-se necessária a criação de soluções criativas nos contextos organizacionais.

Na direção proposta, para enfrentar a sociedade moderna, as organizações precisam ser ágeis e enxutas, focadas nos seus clientes, ter amplo conhecimento do negócio e habilidades para tomadas de decisão em ambientes de maior complexidade. Logo, demandam novos princípios de organização, pautados na comunicação ponta a ponta, na estruturação flexível do trabalho em times e projetos e na avaliação de desempenho por resultados (BRATTON e GOLD, 2017).

Em linhas gerais, o conjunto desses princípios aproxima-se do conceito de modelo organicista de organização proposto por Burns e Stalker (1961), que defendem, em oposição ao modelo mecanicista, a transformação organizacional para a adoção de estruturas mais flexíveis e adaptáveis a contextos de constante mudança e inovação.

Nesse contexto, como destacado por Markert (2000), o desafio das organizações será identificar, atrair e reter profissionais que disponham de características para lidar com esse cenário. A exigência a partir da integração de tarefas e trabalhos é por profissional com comportamento independente na solução de problemas, capacidade de trabalhar em grupo e pensar a partir de sistemas cada vez mais interligados.

Calcado em abordagem proposta por Eboli (1996), Sant'Anna, Moraes e Kilimnik (2005), utilizando-se de técnicas estatísticas multivariadas, procedem à validação dos indicadores de modernidade originalmente formulados por aquela autora em três dimensões: a modernidade administrativa e das práticas de gestão de pessoas, a modernidade política e a modernidade cultural. 
Para fins desta pesquisa, foi considerada a escala revalidada para a realidade brasileira por Sant'Anna et al. (2017), contemplando os itens constantes no Quadro 2.

\section{QUADRO 2 - INDICADORES DE MODERNIDADE ORGANIZACIONAL}

\section{MODERNIDADE ADMINISTRATIVAE DE PRÁTICAS DE GESTÃO DE PESSOAS}

O SISTEMA DE REMUNERAÇÃO DA ORGANIZAÇÃO RECOMPENSA OS ATOS DE COMPETÊNCIA.

A ORGANIZAÇÃO É FORTEMENTE ORIENTADA PARA RESULTADOS.

HÁ UM SISTEMA DE AVALIAÇÃO QUE PERMITE DIFERENCIAR O BOM E O MAU DESEMPENHO.

A ORGANIZAÇÃO EQUILIBRA ADEQUADAMENTE A PREOCUPACุÃO COM RESULTADOS FINANCEIROS, COM AS PESSOAS E COM A INOVAÇÃO.

AS POLÍTICAS E PRÁTICAS DE RECURSOS HUMANOS ESTIMULAM AS PESSOAS A SE PREOCUPAREM COM A APRENDIZAGEM CONTÍNUA.

OS PRINCIPAIS CRITÉRIOS PARA PROMOC̦ÃO SÃO A COMPETÊNCIA E A PRODUTIVIDADE DA PESSOA.

A ORGANIZAÇÃO COMBINA DE FORMA EQUILIBRADA A UTILIZAC̣ÃO DE TECNOLOGIAS AVANÇADAS COM A CRIATIVIDADE DAS PESSOAS.

A TECNOLOGIA EMPREGADA FAVORECE A INTERAÇÃO ENTRE PESSOAS E ÁREAS.

AS POLÍTICAS E PRÁTICAS DA ORGANIZAÇÃO ESTIMULAM QUE AS PESSOAS ESTEJAM SEMPRE BEM INFORMADAS E ATUALIZADAS.

A ESTRATÉGIA, MISSÃO, OBJETIVOS E METAS DA ORGANIZAÇÃO SÃO CLARAMENTE DEFINIDOS.

AS POLÍTICAS E PRÁTICAS DE RECURSOS HUMANOS DA ORGANIZAÇÃO ESTIMULAM O DESENVOLVIMENTO PESSOAL E PROFISSIONAL.

DE MODO GERAL, OS EMPREGADOS SABEM O QUE DEVEM FAZER PARA COLABORAR COM OS OBJETIVOS DA ORGANIZAÇÃO.

O PROCESSO DECISÓRIO NA ORGANIZAÇÃO É DESCENTRALIZADO.

A ORGANIZAC̣ÃO FAVORECE A AUTONOMIA PARA TOMAR DECISÕES.

NO QUE SE REFERE AO ASPECTO POLÍTICO, O REGIME QUE VIGORA NA ORGANIZAÇÃO PODE SER CARACTERIZADO COMO DEMOCRÁTICO.

OS PROCESSOS DE TOMADA DE DECISÃO SÃO PARTICIPATIVOS E TRANSPARENTES.

A ORGANIZAC̣ÃO CONTA COM SISTEMAS DE GESTÃO PARTICIPATIVOS QUE ESTIMULAM A INICIATIVA E AC̣ÃO DAS PESSOAS.

A ORGANIZAÇÃO ADMITE A DIVERSIDADE DE COMPORTAMENTOS E RESPEITA AS DIFERENÇAS INDIVIDUAIS.

O AMBIENTE DE TRABALHO FACILITA O RELACIONAMENTO ENTRE AS PESSOAS, MESMO DE NÍVEIS HIERÁRQUICOS DIFERENTES.

MODERNIDADE CULTURAL O CLIMA INTERNO DA ORGANIZAÇÃO ESTIMULA IDEIAS NOVAS E CRIATIVAS.

O CLIMA INTERNO DA ORGANIZAÇÃO ESTIMULA QUE AS PESSOAS ESTEJAM EM CONTÍNUO PROCESSO DE APRENDIZAGEM, NO SEU DIA A DIA DE TRABALHO. 


\section{Metodologia}

Quanto ao método, a pesquisa pode ser caracterizada como de abordagem quantitativa e caráter descritivo, conduzida por meio do método e técnica de survey, utilizando-se de escalas padronizadas de respostas graduais do tipo Likert, de 11 pontos, junto a escritórios de advocacia da capital belinense (Top Ten OAB-PA). Os objetos de observação (advogados) desses escritórios foram submetidos a levantamento censitário (KERLINGER, 1980, p. 171). Convém registrar que a escolha de escritórios em Belém (PA) deve-se a iniciativa da Ordem dos Advogados (OAB-Pará), pioneira no Brasil na inserção, em sua estrutura organizacional, de comissão destinada ao desenvolvimento de estudos, pesquisas e instrumentos de capacitação de advogados e dirigentes de escritórios de advocacia em competências gerenciais e de liderança, incluindo ênfase nas chamadas soft-skills, em face da transição em curso para a "Economia Digital" ou "Quarta Revolução Industrial" e seus impactos sobre os perfis profissionais requeridos ao exercício da profissão, bem como de modelos de negócios e formas emergentes de prestação de serviços advocatícios.

O questionário foi composto por três blocos de questões. O Bloco I é formado por 23 questões destinadas a mensurar o grau de modernidade organizacional, particularmente a modernidade administrativa e das práticas de gestão de pessoas, a modernidade política e a modernidade cultural (SANT'ANNA et al., 2017).

Já o Bloco II, constituído por 37 itens, orientou-se à mensuração do estilo de liderança. Cabe salientar que os itens integrantes da escala resultaram de levantamento bibliográfico sistemático sobre o tema "liderança relacional" ("relational leadership"), identificando na literatura os atributos mais reiteradamente apontados como centrais ao seu exercício. Após consolidação, os itens foram submetidos à avaliação de três pesquisadores brasileiros no campo da liderança, os quais analisaram os itens e procederam a sugestões de alterações, incluindo supressão, adição e/ou junção de itens, assim como a melhorias na forma de apresentação. Depois dessa avaliação, o instrumento foi alterado, não se verificando divergências entre os especialistas quanto aos itens propostos. A partir da análise pelos especialistas, os itens foram formatados na escala.

Por fim, o Bloco III foi constituído por questões sociodemográficas e profissionais acerca dos respondentes.

Convém registrar que o questionário, previamente à sua aplicação, também foi submetido a pré-teste junto a advogados vinculados aos escritórios a serem investigados. A iniciativa teve como intuito avaliar a adequação empírica e contextual das escalas (conteúdo), bem como 
a compreensão das questões propostas (forma). Como resultado, alterações na forma de apresentação de alguns itens foram introduzidas, visando deixar as frases mais claras e aderentes ao vocabulário adotado pelos respondentes. O conjunto dos itens, no entanto, mesmo relativo ao universo da gestão, mostrou-se de conhecimento dos respondentes, não sendo sugeridos detalhamentos, exclusão ou adição de itens.

Isso posto, o instrumento foi formatado e sua versão final submetida a advogados de sete escritórios de advocacia situados na cidade de Belém (Pará, Brasil). O universo consta dos dez maiores escritórios de advocacia de diferentes áreas de atuação jurídica de Belém, conforme relação disponibilizada pela Comissão de Estratégias e Liderança em Escritórios de Advocacia da Ordem dos Advogados Secção Pará (OAB-PA), e dos dez principais escritórios com sede na capital paraense (Top Ten), considerando faturamento anual, tamanho da carteira de clientes e número de advogados associados. Desse universo, sete escritórios aceitaram participar da pesquisa, tendo sido encaminhados 150 questionários. Como retorno da aplicação censitária, on-line, foram obtidos 50 questionários preenchidos e válidos (33,3\%).

Conforme disposto na Tabela 1, em termos de perfil, a maioria dos respondentes revelou-se do sexo masculino (66\%), com idade entre 21 e 25 anos (44\%) e solteiros(as) (82\%). Em relação à escolaridade, os participantes têm, majoritariamente, pós-graduação (40\%) e atuam em tempo inferior a três anos nos escritórios investigados (70\%).

TABELA 1 - RESULTAdOS DEMOGRÁFICOS SOBRE OS PARTICIPANTES DA PESQUISA

\begin{tabular}{llll} 
VARIÁVEL & CATEGORIAS & FABS & $\%$ \\
\hline GÊNERO & FEMININO & 17 & $34 \%$ \\
& MASCULINO & 33 & $66 \%$ \\
\hline FAIXA ETÁRIA & ATÉ 20 ANOS & 4 & $8 \%$ \\
& DE 21 A 25 ANOS & 22 & $44 \%$ \\
& DE 26A A0 ANOS & 19 & $38 \%$ \\
& DE 31 A35 ANOS & 5 & $10 \%$ \\
\hline ESTADO CIVIL & CASADO(A) & 8 & $16 \%$ \\
& DIVORCIADO(A) OU SEPARADO(A) & 1 & $2 \%$ \\
& SOLTEIRO(A) & 41 & $82 \%$ \\
\hline ESCOLARIDADE MAIS ALTAALCANC̦ADA & CURSANDO A GRADUAC̦ÃO & 15 & $30 \%$ \\
& GRADUAC̦ÃO & 9 & $18 \%$ \\
& EXTENSÃO & 1 & $2 \%$ \\
& PÓS-GRADUAÇÃO (ESPECIALIZAÇÕES/MBA) & 20 & $40 \%$ \\
& MESTRADO & 4 & $8 \%$ \\
& DOUTORADO & 1 & $2 \%$ \\
\hline
\end{tabular}




\begin{tabular}{llll} 
VARIÁVEL & CATEGORIAS & FABS & $\%$ \\
\hline TEMPO EM QUE ESTÁ NO ESCRITÓRIO ATUAL & ATÉ 1 ANO & 16 & $32 \%$ \\
& DE 1 A 3 ANOS & 19 & $38 \%$ \\
& DE 3 A 5 ANOS & 4 & $8 \%$ \\
& DE 5A 10 ANOS & 9 & $18 \%$ \\
& DE 10A 15 ANOS & 2 & $4 \%$ \\
\hline ATUALMENTE, QUAL SUA POSII̦ÃO NO & ADVOGADO ASSOCIADO & 2 & $4 \%$ \\
ESCRITÓRIO EM QUE VOCÊ TRABALHA? & ADVOGADO JÚNIOR & 6 & $12 \%$ \\
& ADVOGADO PLENO & 5 & $10 \%$ \\
& ADVOGADO SÊNIOR & 2 & $4 \%$ \\
& COORDENADOR DE ÁREA & 3 & $6 \%$ \\
& ESTAGIÁRIO & 16 & $32 \%$ \\
& GESTOR NÃO ADVOGADO & 1 & $2 \%$ \\
& SÓCIO & 15 & $30 \%$ \\
\hline
\end{tabular}

Nota: Fabs significa frequência absoluta.

Fonte: Dados da pesquisa.

Para o tratamento dos dados obtidos foi, inicialmente, calculado o Coeficiente de Validade de Conteúdo (CVC), destinado a verificar a adequação dos indicadores da escala de liderança relacional. Por meio do CVC, cada item da escala é computado em adição a um indicador de facilidade de entendimento para o público em questão. Os resultados obtidos foram, na sequência, submetidos ao cálculo do Coeficiente de Correlação Intraclasse (ICC) (ANUNCIAÇÃO et al., 2018; ALEXANDRE e COLUCI, 2011). Após, foi calculada a fidedignidade da escala. Para tal, a consistência interna foi estimada pela correlação entre o conjunto dos itens da escala. Posteriormente, foram calculadas as medidas descritivas, incluindo médias e desvios-padrão (FURR, 2011).

Finalmente, para explorar os possíveis componentes lineares relacionados à variabilidade dos dados à distribuição dos resultados e a aspectos multivariados (Análise de Componentes Principais) foi aplicado o teste de correlação p (MARÔCO, 2010).

Em relação à escala de modernidade organizacional, foi utilizado o modelo criado e validado por Sant'Anna, Moraes e Kilimnik (2005) para o contexto brasileiro e posteriormente revalidado por Sant'Anna et al. (2016).

Finalmente, modelos lineares gerais foram realizados com o fim de analisar a relação entre modernidade organizacional e liderança relacional (HOWELL, 2011). Convém registrar que o nível de significância foi estipulado em 0,05 e todas as análises foram realizadas por meio do software de tratamento estatístico de dados R 3.6.1, com auxílio dos pacotes Tidyverse (WICKHAM, 2016), APA Tables (STANLEY e SPENCE, 2018) e Psych (REVELLE, 2018). 


\section{ApresentaçÃo e ANÁlise de dAdOS}

A partir do conjunto dos dados obtidos, foi mensurado o grau de modernidade organizacional do conjunto de escritórios de advocacia investigados. Os resultados para a dimensão modernidade administrativa e das práticas de gestão de pessoas são apresentados no Gráfico 1.

\section{GRÁfico 1 - ProporÇÃo de RESPOSTAS RELACIONADAS À dimensÃo "MODERNIDADE ADMINISTRATIVA E DAS PRÁTICAS DE GESTÃO DE PESSOAS"}

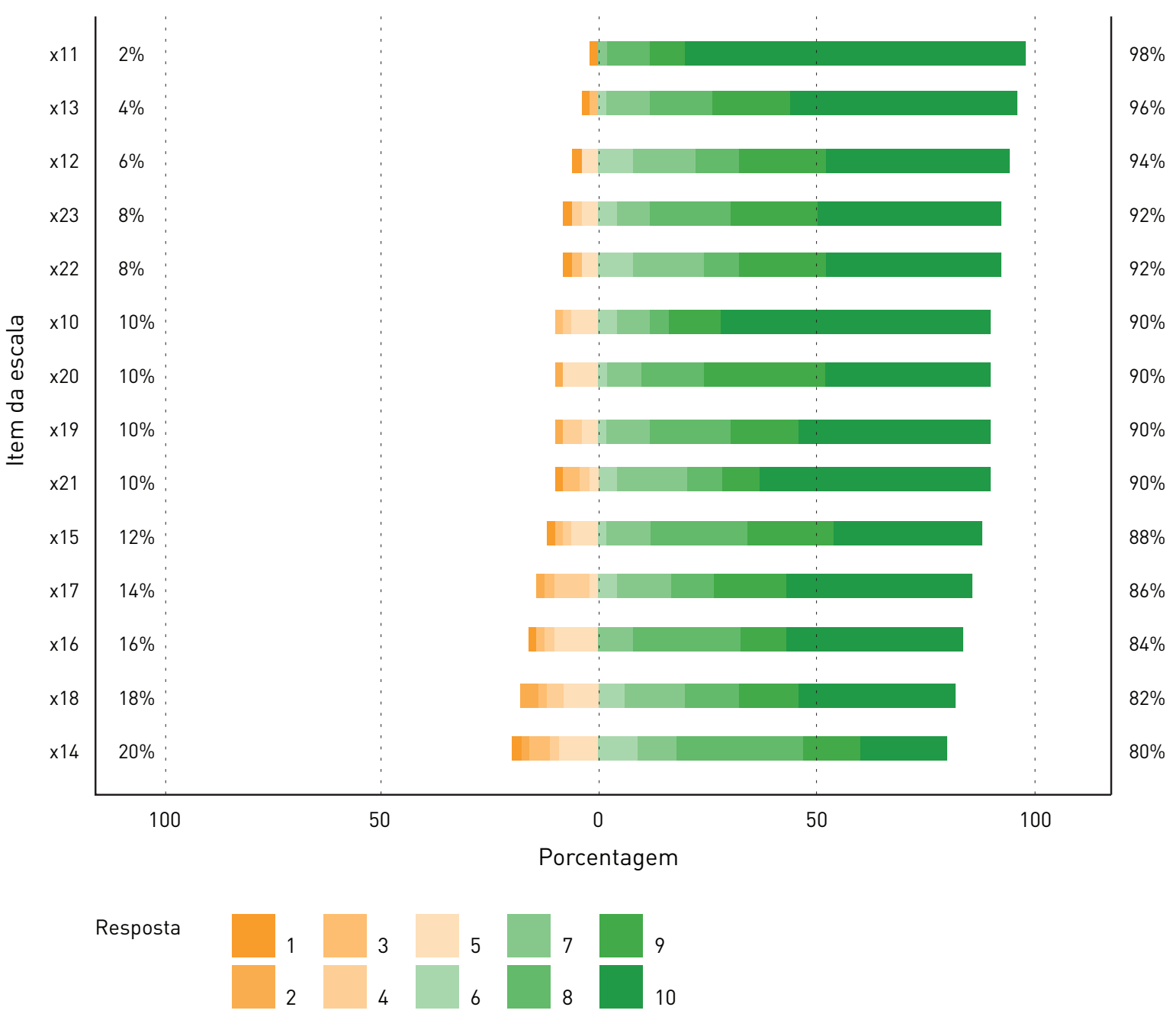

Nota: x10 - A organização admite a diversidade de comportamentos e respeita as diferenças individuais; x11 - 0 ambiente de trabalho facilita o relacionamento entre as pessoas, mesmo de níveis hierárquicos diferentes; x12 - 0 sistema de remuneração da organização recompensa os atos de competência; x13 - A organização é fortemente orientada para resultados; x14 - Há um sistema de avaliação que permite diferenciar o bom e o mau desempenho; x15 - A organização equilibra a preocupação com resultados financeiros, com as pessoas e com a inovação; x16 - As políticas e práticas de RH estimulam as pessoas a se preocupar com a aprendizagem contínua; x17 - Os principais critérios para promoção são a competência e a produtividade da pessoa; x18 - A organização combina de forma equilibrada a utilização de tecnologias com a criatividade das pessoas; x19 - A tecnologia empregada favorece a interação entre pessoas e áreas; x20 - As políticas e práticas da organização estimulam que as pessoas estejam bem informadas e atualizadas; x21 - A estratégia, a missão, os objetivos e as metas da organização são claramente definidos; x22 - As políticas e práticas de RH da organização estimulam o desenvolvimento pessoal e profissional; x23 - De modo geral, os empregados sabem o que devem fazer para colaborar com os objetivos da organização.

Fonte: Dados da pesquisa. 
Pelos dados do Gráfico 1, destaca-se como item de maior escore na dimensão modernidade administrativa e de práticas de gestão de pessoas o grau em que o "ambiente de trabalho facilita o relacionamento entre as pessoas, mesmo de níveis hierárquicos diferentes", com média de 9,48. Já o indicador com menor escore refere-se à inexistência de "sistema de avaliação que permite diferenciar o bom e o mau desempenho" $(6,66)$.

Análises similares para a dimensão modernidade política (Gráfico 2) apresentam como maior escore a prevalência de "regime interno caracterizado como democrático" $(8,9)$. Já o menor escore foi atribuído ao grau em que o "processo decisório é percebido como descentralizado" $(7,4)$.

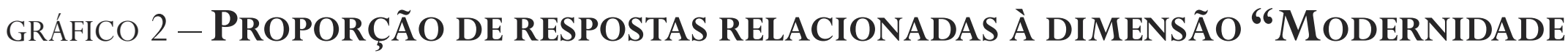 POLÍTICA"}

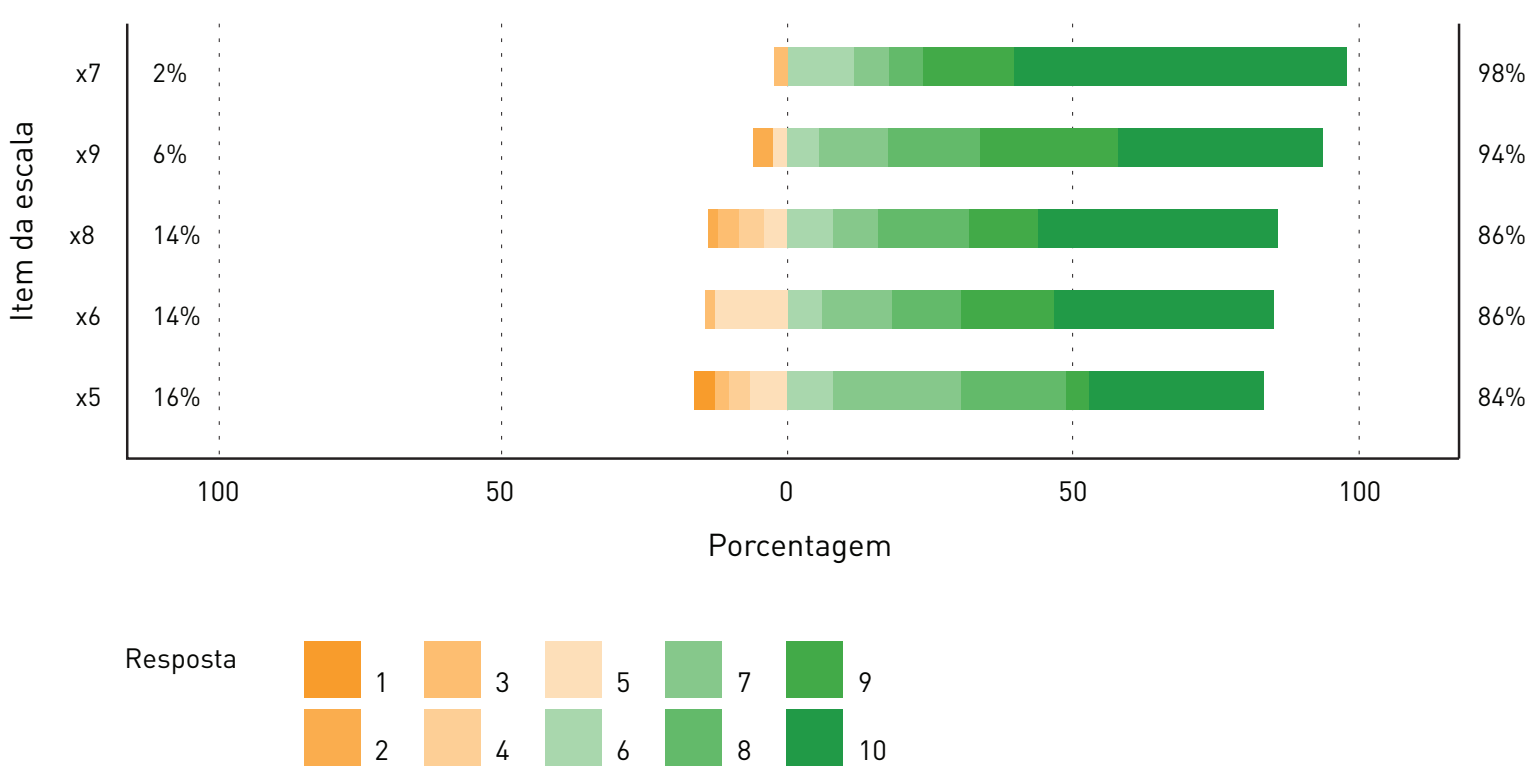

Nota: x5 - 0 processo decisório na organização é descentralizado; x6 - A organização favorece a autonomia para tomar decisões; $x 7$ - 0 regime que vigora na organização pode ser caracterizado como democrático; 8 - 0s processos de tomada de decisão são participativos e transparentes; $x 9$ - A organização conta com sistemas de gestão participativos que estimulam a iniciativa e ação das pessoas.

Fonte: Dados da pesquisa.

Em relação à modernidade cultural, o maior escore, conforme apresentado no Gráfico 3, é verificado junto ao item destinado a mensurar o grau em que "a organização encoraja a iniciativa e responsabilidade individual" $(9,2)$. O menor escore, por sua vez, é registrado em relação à existência de clima interno de estímulo à aprendizagem e desenvolvimento contínuos $(8,7)$. 


\section{GrÁfico 3 - Proporção de ReSPOSTAS RelacionadAs À dimensão "ModernidAde}

\section{CULTURAL"}



Nota: x1 - 0 clima interno da organização estimula ideias novas e criativas; x2 - 0 clima interno da organização estimula que as pessoas estejam em contínuo processo de aprendizagem; x3 - Na organização, há um clima estimulante para que as pessoas realizem suas atividades, buscando se superar; x4 - A organização encoraja a iniciativa e responsabilidade individual.

Fonte: Dados da pesquisa.

Comparando o índice atribuído a cada uma das dimensões de modernidade investigadas, tem-se o maior escore atribuído à modernidade cultural $(8,9)$, seguido da modernidade administrativa e de gestão de pessoas $(8,3)$ e, por fim, a modernidade política $(8,2)$.

No que tange à análise da distribuição do conjunto dos itens da escala de modernidade, é possível identificar uma pequena assimetria à esquerda, estando, todavia, a maior parte da distribuição concentrada à direita (escores mais elevados), com valores de mediana superiores à média (Figura 1). Achado similar é constatado em relação à escala de liderança relacional (Figura 2). 
Figura 1 - DistribuiçÃo dos ReSUltados dA EscAla de MODERNidAde
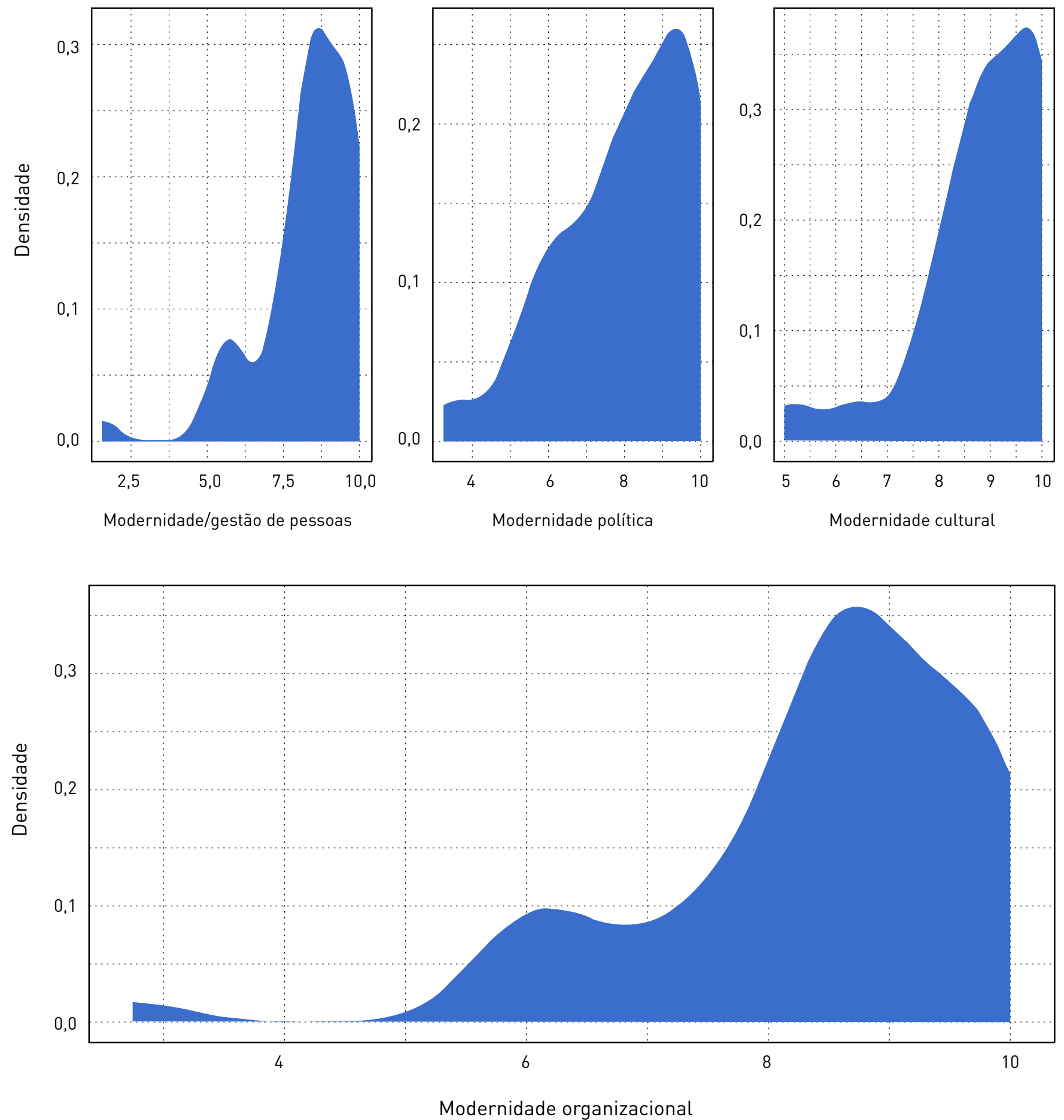

Fonte: Dados da pesquisa.

Com base nos dados das Figuras 1 e 2, registram-se também valores elevados para ambas as escalas, indicando alto grau de aderência entre os itens propostos, na percepção dos respondentes. 
FIGURA 2 - DisTribuiçÃo dos RESULTAdOS DA ESCALA DE LIDERANÇA RELACIONAL

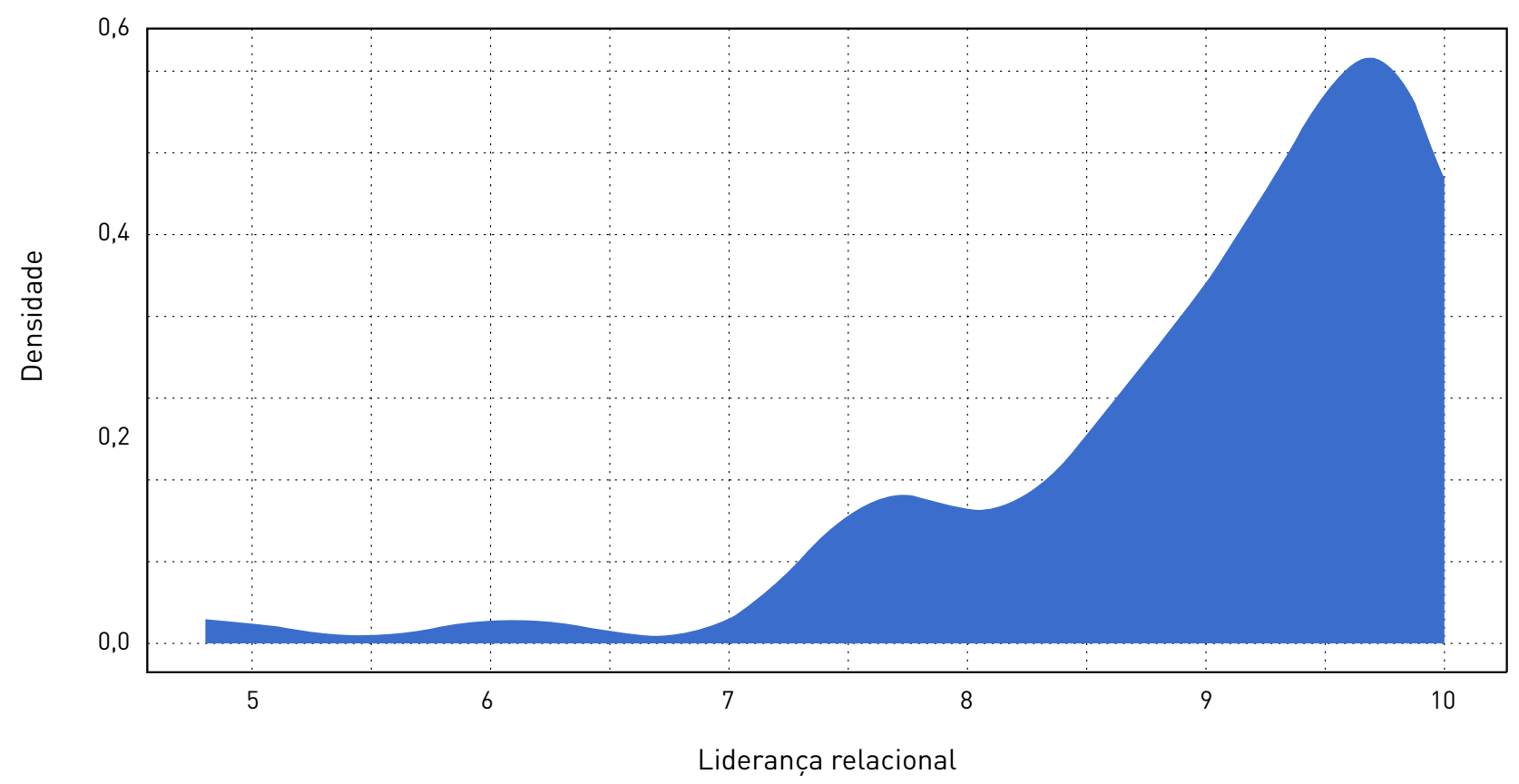

Fonte: Dados da pesquisa.

Além disso, análise comparativa entre os constructos modernidade de políticas e práticas organizacionais e liderança relacional, conduzida por meio do cálculo da ANOVA, envolvendo medidas repetidas de uma via (one-way within-subjects), aponta para diferenças expressivas entre os itens de liderança e os fatores da escala de modernidade $(F(3,147)=15$, p $<0,01)$, indicando valores significativamente superiores para as dimensões "modernidade administrativa e das práticas de gestão de pessoas" e "modernidade política” (Tabela 2).

\section{TABELA 2 - RESULTADOS DESCRITIVOS DOS FATORES}

\begin{tabular}{llllll} 
& $\begin{array}{l}\text { LIDERANÇA } \\
\text { RELACIONAL }\end{array}$ & $\begin{array}{l}\text { MODERNIDADE } \\
\text { TOTAL }\end{array}$ & $\begin{array}{l}\text { MODERNIDADE } \\
\text { CULTURAL }\end{array}$ & $\begin{array}{l}\text { MODERNIDADE } \\
\text { ADMINISTRATIVA }\end{array}$ & $\begin{array}{l}\text { MODERNIDADE } \\
\text { POLITICA }\end{array}$ \\
\hline M & 9,05 & 8,39 & 8,88 & 8,33 & 1,18 \\
\hline DP & 1,06 & 1,43 & 1,2 & 1,61 & 3,8 \\
\hline MIN & 4,78 & 2,74 & 5 & 1,64 & 7 \\
\hline Q1 & 8,7 & 7,87 & 8,5 & 7,86 & 8,4 \\
\hline MED & 9,41 & 8,7 & 9 & 8,68 & 9,64 \\
\hline Q3 & 9,84 & 9,48 & 10 & 10 & 9,4 \\
\hline MAX & 10 & 10 & 10 & 9
\end{tabular}

(continua) 
LIDERANÇA RELACIONAL E MODERNIDADE ORGANIZACIONAL EM FIRMAS DE ADVOCACIA DE BELÉM DO PARÁ :

\begin{tabular}{llllll} 
& $\begin{array}{l}\text { LIDERANÇA } \\
\text { RELACIONAL }\end{array}$ & $\begin{array}{l}\text { MODERNIDADE } \\
\text { TOTAL }\end{array}$ & $\begin{array}{l}\text { MODERNIDADE } \\
\text { CULTURAL }\end{array}$ & $\begin{array}{l}\text { MODERNIDADE } \\
\text { ADMINISTRATIVA }\end{array}$ & $\begin{array}{l}\text { MODERNIDADE } \\
\text { POLITICA }\end{array}$ \\
\hline MAD & 0,68 & 1,19 & 1,11 & 1,38 & 1,78 \\
\hline IQR & 1,11 & 1,53 & 1,5 & 1,73 & 0,4 \\
\hline CV & 0,12 & 0,17 & 0,14 & 0,19 & $-0,81$ \\
\hline ASS. & $-1,87$ & $-1,52$ & $-1,42$ & $-1,75$ & $-0,11$ \\
\hline CURT. & 4,1 & 3,09 & 1,92 & 4,1 & \\
\hline
\end{tabular}

Nota: M: Média; DP: desvio-padrão; Min: Valor mínimo obtido; Q1: $1^{\circ}$ quartil; Med: Mediana; Q3: $3^{\circ}$ quartil; Max: Valor máximo obtido; MAD: Desvio-absoluto da mediana; IQR: Intervalo interquartil; CV: Coeficiente de Variação; Ass.: Coeficiente de Assimetria; Curt.: Coeficiente de Curtose.

Fonte: Dados da pesquisa.

Quanto ao cálculo da correlação entre a liderança relacional e as dimensões de modernidade organizacional, os resultados apontam para correlações positivas e significativas no conjunto dos fatores investigados, conforme explicitado na Tabela 3.

TABELA 3 - RESULTADOS CORRELACIONAIS DE LIDERANÇA RELACIONAL E MODERNIDADE ORGANIZACIONAL

\begin{tabular}{lllll} 
& LIDERANC̣A TOTAL & $\begin{array}{l}\text { MODERNIDADE } \\
\text { CULTURAL }\end{array}$ & $\begin{array}{l}\text { MODERNIDADE } \\
\text { DE GESTÃO }\end{array}$ & $\begin{array}{l}\text { MODERNIDADE } \\
\text { POLÍtICA }\end{array}$ \\
\hline LIDERANÇA TOTAL & 1 & & & \\
\hline MODERNIDADE CULTURAL & 0,79 & 1 & 1 & 1 \\
\hline MODERNIDADE DE GESTÃO & 0,85 & 0,83 & 0,72 & 1 \\
\hline MODERNIDADE POLÍTICA & 0,65 & 0,58 &
\end{tabular}

Fonte: Dados da pesquisa.

\section{DiscuSSÃo E CONCLUSÕES}

A partir da investigação de relações entre os constructos liderança relacional e modernidade organizacional em setor ainda pouco explorado nos debates acadêmicos e institucionais - as organizações profissionais (professional services), como as do segmento de prestação de serviços 
jurídicos (BORCK, 2008) -, pôde-se constatar que: (i) há maiores escores de modernidade cultural em relação às dimensões modernidade administrativa e das práticas de gestão de pessoas e modernidade política, sugerindo, pelo menos no nível do discurso, uma maior abertura aos modelos de gestão contemporâneos; (ii) não obstante, registra-se a prevalência de menores escores concernentes à dimensão política, o que reflete uma dinâmica de modernização ainda de base conservadora; (iii) há correlação positiva e significativa entre liderança relacional e modernidade organizacional, indicando aspectos como o exercício de estilo de liderança mais coletivo e distribuído, o que tende a favorecer o desenvolvimento de políticas e práticas mais aderente às novas configurações e aos modelos de negócios, centrados em arquiteturas mais flexíveis e horizontalizadas.

Ainda no que se refere à instância da modernidade organizacional, é possível ressaltar quanto à dimensão cultural significativa ênfase em aspectos como a iniciativa e a responsabilidade individual. Esses achados muito provavelmente se relacionam ao fato de os escritórios de advocacia se constituírem em organizações intensivas em capital humano, tendo como valores centrais de atuação a autonomia e a competência técnica de seus profissionais (CASTELO JR. e TURETA, 2014).

Soma-se a isso os próprios achados apontarem para a difusão, nos escritórios de advocacia investigados, de modelos contemporâneos de gestão (management), sintomatizados na prevalência de profissionais mais jovens e com pouco tempo de casa (SANT'ANNA et al., 2016). Já no que tange ao exercício da liderança, os achados sugerem significativa presença de elementos associados ao estilo relacional. Em linhas gerais, pode-se constatar elevada presença de características de uma liderança coletiva e distribuída, superando estilos de liderança fortemente centrados no comando-controle e na orientação a tarefas (CLEARY et al., 2018; UHL-BIEN, 2006). Constata-se, pela literatura revisada, que aspectos associados à natureza do trabalho e à necessidade de ambiências organizacionais com demanda por maiores níveis de autonomia e flexibilidade - como as professional services - tendem a se caracterizar pela presença de comportamentos e estilos de liderança mais relacionais (SANT'ANNA et al., 2017; QUICK, 2014).

Ainda no que concerne ao estilo de liderança relacional, uma importante contribuição deste artigo consiste na proposição de um conjunto de indicadores passível de ser aplicado em sua mensuração. Por meio desses indicadores, configura-se possível acessar um amplo leque de variáveis contextuais, organizacionais e pessoais que, mensuradas, podem constituir recurso valioso à identificação, atração e retenção de talentos mais aderentes às demandas contemporâneas de organizações e instituições envolvidas com a instância dos serviços jurídicos. Igualmente, a constatação de correlação positiva e significativa entre modernidade organizacional e liderança relacional traz à tona diversas possibilidades de introdução de políticas e práticas organizativas mais afins aos desafios da gestão desse importante segmento, em profunda transformação.

Quanto a limitações do estudo, cabe salientar que a dimensão cultural - e a dimensão das culturas nacional e local - constitui fator relevante à compreensão das dinâmicas e dos 
comportamentos inerentes a qualquer estudo em ciências sociais aplicadas. Há que se considerar, todavia, que, diferentemente de contextos históricos passados, fatores como a disseminação de tecnologias de informação e comunicação, a facilitação dos meios de transporte, o intercâmbio e a formação contínua em diferentes contextos socioeconômicos e culturais tendem a minimizar eventuais limitações associadas à geografia física. Ao contrário, podem evidenciar tendências ao isomorfismo e à reprodução de discursos hegemônicos, com acesso cada vez mais amplo entre profissionais de mesma ocupação a redes de contato global, redes sociais, capacitação em instituições com bases curriculares similares, intercâmbios profissionais, bibliografias, eventos e discursos homogêneos, vivências internacionais e formação de docentes em mesmos programas. Em outros termos, o profissional tende a ser mais desterritorializado e global, mais virtualmente nômade e isomorfo.

Revelam-se interessantes estudos futuros que abranjam outros grupos amostrais, em diferentes geografias e contextos socioculturais. De toda forma, os achados deste estudo indicam a relevância de maior consideração por parte dos escritórios de advocacia das transformações em curso associadas à chamada Quarta Revolução Industrial, em particular no que diz respeito à profissionalização do aparato de gestão, considerando os impactos das novas tecnologias sobre os fundamentos dos negócios, os desenhos e as estruturas organizativas e os estilos de gestão e liderança.

Isso poderá permitir a construção e sustentação de dinâmicas organizacionais com maior aderência (fitness) entre suas principais instâncias - política, cultural, administrativa - e estilos de liderança - relacionais -, capazes de dar respostas mais efetivas à identificação, ao desenvolvimento, à mobilização e à retenção de competências organizacionais e pessoais distintivas, diante de ambientes de negócios marcados por um ritmo de disrupções sem precedentes. Nesses ambientes, a criação, a inovação e o que de mais singular há no humano - seus desejos, sua criatividade, seu engajamento - podem se manifestar em fatores centrais de diferenciação e vantagem competitivas, em contraposição a ambiências organizacionais mecanicistas, prescritivas, padronizadas, autoritárias e centralizadas, comumente associadas a certos imaginários de management e a estilos de dominação - não de liderança -, ameaçados pelas atuais tecnologias digitais e por formas outras de inteligência não humana.

Em suma, esse parece o desafio da gestão, e em particular da liderança, na transição em curso das organizações para a Economia 4.0, Economia Digital, Revolução 4.0, Quarta Revolução Industrial, Modernidade Tardia. Independentemente da inexistência de rótulos, um aspecto parece evidenciar-se: os profissionais e os escritórios de advocacia não passarão incólumes a essa onda de transformações. 


\section{REFERÊNCIAS}

ALEXANDRE, Neusa Maria Costa; COLUCI, Marina Zambon Orpinelli. Validade de conteúdo nos processos de construção e adaptação de instrumentos de medidas. Ciência \& Saúde Coletiva, Rio de Janeiro, v. 16, n. 7, p. 3061-3068, 2011. Disponível em: http://bit.ly/33hjTrb. Acesso em: 22 nov. 2019.

ANDERSON, Chris. Makers: The New Industrial Revolution. New York: Crown Business, 2012.

ANUNCIAÇÃO, Luis et al. Redução da Escala Tendência Empreendedora Geral (TEG-FIT) a partir do Coeficiente de Validade de Conteúdo (CVC) e Teoria da Resposta ao Item (TRI). Revista Eletrônica de Ciência Administrativa, Curitiba, v. 17, n. 2, p. 192-207, 2018.

BASS, Bernard M. Handbook of Leadership: Survey of Theory and Research. New York: The Free Press, 1990.

BORCK, Nefhar. Crescimento consciente. Revista Advogados Mercados \& Negócios, São Paulo, ano 3, n. 17, p. 35, 2008 .

BRATTON, John; GOLD, Jeff. Human Resource Management:Theory and Practice. Macmillan Education, 2017.

BRYNJOLFSSON, Erik; MCAFEE, Andrew. Race against the Machine. Boston, MA: MIT Sloan Management, 2011.

BURNS, Tom; STALKER, George. The Management of Innovations. London: Tavistock, 1961.

BURNS, James MacGregor. Leadership. New York: Harper \& Row, 1978.

CASTElO JR., Clóvis; TURETA, César. A nova advocacia pós-profissional e a modernização das grandes sociedades de advocacia empresarial brasileiras. Revista de Administração Contemporânea, v. 18, n. 6 , p. 813-831, 2014.

CHRISTENSEN, Clayton Magleby. The Innovator's Dilemma: When New Technologies Cause Great Firms to Fail. Cambridge, MA: Harvard Business Review Press, 2006.

CLEARY, Susan et al. Enabling Relational Leadership in Primary Healthcare Settings: Lessons from the DIALHS Collaboration. Health Policy and Planning, London, v. 33, supl. 2, p. 65-74, 2018.

CUNLIFFE, Ann L.; ERIKSEN, Matthew. Relational Leadership. Human Relations, Thousand Oaks, v. 64, n. 11, p. $1425-1449,2011$. 
DAY, David V.; HARRISON, Michelle M. A Multilevel, Identity-based Approach to Leadership Development. Human Resource Management Review, Amsterdam, v. 17, n. 4, p. 360-373, 2007.

EBOLI, Marisa P. Modernidade na gestão de bancos. 1996. Tese (Doutorado em Administração) - Faculdade de Economia e Administração, Universidade de São Paulo, São Paulo, 1996.

FREY, Carl Benedikt; OSBORNE, Michael A. The Future of Employment: How Susceptible Are Jobs to Computadorizing. Technological Forecasting and Social Change, v. 114, p. 254-280, 2010.

FURR, R. Michael. Scale Construction and Psychometrics for Social and Personality Psychology. London: SAGE Publications, 2011.

GONÇALVES, José Ernesto Lima. Os novos desafios da empresa do futuro. Revista de Administração de Empresas, São Paulo, v. 37, n. 3, p. 10-19, 1997.

GONÇALVES, Marco Antonio P. Atuação estratégica dos departamentos jurídicos. In: INVESTIDURA. Investidura: portal jurídico. Florianópolis: Investidura, 2008. Disponível em: http: / /bit.ly/2OAGwl0. Acesso em: 2 jul. 2019.

GONÇALVES, Ricardo P. O papel do advogado nas empresas. Administradores.com. João Pessoa, 13 abr. 2012. Disponível em: https: / /administradores.com.br/artigos/o-papel-do-advogado-nas-empresas. Acesso em 22 out. 2021.

GREENWOOD, Royston; LACHMAN, Ran. Change as an Underlying Theme in Professional Service Organizations: An Introduction. Organization Studies, Thousand Oaks, v. 17, n. 4, p. 563-572, 1996.

HOWELL, David C. Fundamental Statistics for the Behavioral Sciences. Belmont: Wadsworth Cengage Learning, 2011.

ISMAIL, Salim. Exponential Organizations: Why New Organizations Are Ten Times Better, Faster, and Cheaper than Yours (and What to Do about It). New York: Diversion, 2014.

KAPLAN, Jerry. Humans Need not Apply: A Guide to Wealth and Work in the Age of Artificial Intelligence. New Haven (CT): Yale University Press, 2017.

KELLY, Kevin. The Inevitable: Understanding the Twelve Technological Forces that Will Shape our Future. New York: Penguin Books, 2016. 
KERLINGER, Fred Nichols. Metodologia da pesquisa em ciências sociais: um tratamento conceitual. São Paulo: EPU, 1980.

LEE, Timothy B. The Productivity Paradox: Why We're Getting More Innovation but Less Growth. New York: Vox Media, 2016.

MARKERT, Werner. Novos paradigmas do conhecimento e modernos conceitos de produção: implicações para uma nova didática na formação profissional. Educação e Sociedade, Campinas, v. 21, n. 72, p. 177-196, 2000.

MARÔCO, João. Análise de equações estruturais: fundamentos teóricos, software \& aplicações. Pêro Pinheiro: ReportNumber, 2010.

MINTZBERG, Henry. Criando organizações eficazes: estrutura em cinco configurações. 2. ed. São Paulo: Atlas, 2003.

MIRANDA, Adriano Becattini de. Liderança e valores organizacionais: um estudo junto a servidores públicos municipais. 2015. 102 f. Dissertação (Mestrado em Administração) - Pontifícia Universidade Católica de Minas Gerais, Belo Horizonte, 2015.

MORGAN, Jacob. The Future ofWork: Attract New Talent, Build Better Leaders, and Create a Competitive Organization. Hoboken (NJ): Wiley, 2014.

QUICK, Kathryn. Taking a Relational Turn in Leadership Studies. Public Administration Review, Hoboken, v. 74, n. 4, p. 542-544, 2014.

REVELLE, William. Package "Psych”: Procedures for Psychological, Psychometric and Personality Research. Eugene: R Package, 2018. Disponível em: http://bit.ly/2DduJnt. Acesso em: 25 nov. 2019.

ROSS, Alec. The Industries of the Future. New York: Simon \& Schuster, 2016.

SANT’ ANNA, Anderson de Souza; FERREIRA, Jaqueline; COELHO DOS SANTOS, Tania. Revolução 4.0: uma "radiografia" de países de economia desenvolvida e do Brasil. Revista de Empreendedorismo, Negócios e Inovação, São Bernardo do Campo, v. 4, n. 2, p. 27-50, 2020.

SANT'ANNA, Anderson de Souza; MORAES, Lúcio Flávio Renault de; KILIMNIK Zélia Miranda. Competências individuais, modernidade organizacional e satisfação no trabalho: um estudo de diagnóstico comparativo. RAE-eletrônica, v. 4, n. 1, p. 1-23, 2005. 
SANT'ANNA, Anderson de Souza; NELSON, Reed Eliot; CARVALHO NETO, Antônio Moreira. Fundamentos e dimensões da liderança relacional. DOM: Revista da Fundação Dom Cabral, Nova Lima, v. 9, n. 26, p. 16-21, 2015.

SANT'ANNA, Anderson de Souza et al. Liderança e sustentabilidade: contribuições de estudos sobre dinâmicas socioespaciais de reconversão e requalificação de funções econômicas. Revista de Administração, Contabilidade e Economia, Joaçaba, v. 16, n. 3, p. 1133-1160, 2017.

SANT'ANNA, Anderson de Souza et al. Competências individuais e modernidade organizacional: um estudo comparativo entre profissionais de organizações mineiras e baianas. Gestão \& Produção, São Carlos, v. 23, n. 2, p. 308-319, 2016.

SCHWAB, Klaus. A quarta revolução industrial. São Paulo: Edipro, 2016.

SELEM, L. Advocacia em transformação. Advogados: Mercados \&Negócios, São Paulo, ano 4, n. 22, p. 42 45, 2009.

SRNICEK, Nick; WILLIAMS, Alex. Inventing the Future: Postcapitalism and a World without Work. London: Verso, 2016.

STANLEY, David J.; SPENCE, Jeffrey R. Reproducible Tables in Psychology Using the apaTables Package. Advances in Methods and Practices in Psychological Science, Thousand Oaks, v. 1, n. 3, p. 1-17, 2018. Disponível em: http://bit.ly/33eeeSF. Acesso em: 25 nov. 2019.

SUSSKIND, Richard. The End of Lawyers: Rethinking the Nature of Legal Services. Oxford: Oxford University Press, 2008.

SUSSKIND, Richard; SUSSKIND, Daniel. The Future of the Professions: How Technology Will Transform the Work of Human Experts. Glasgow: Oxford University Press, 2017.

TOURAINE, Alain. Crítica da modernidade. Petrópolis: Vozes, 1994.

UHL-BIEN, Mary. Relational Leadership Theory: Exploring the Social Processes of Leadership and Organizing. The Leadership Quarterly, Amsterdam, v. 17, n. 6, p. 654-676, 2006.

UHL-BIEN, Mary; ARENA, Michael. Leadership for Organizational Adaptability: A Theoretical Synthesis and Integrative Framework. The Leadership Quarterly, v. 29, p. 89-104, 2018. 
WICKHAM, Hadley. Tidyverse: Easily Install and Load the "Tidyverse" Packages. R package version 1.0.0. Boston: RStudios, 2016.

YAMMARINO, Francis J.; DANSEREAU, Fred; KENNEDY, Christina J. A Multiple-Level Multidimensional Approach to Leadership:Viewing Leadership Through an Elephant's Eye. Organizational Dynamics, Amsterdam, v. 29, n. 3, p. 149-163, 2001.

ZAJDSZNAJDER, Luciano. Pós-modernidade e tendências da administração contemporânea. Boletim Técnico do SENAC, Rio de Janeiro, v. 19, n. 3, p. 10-19, 1993.

\section{COMO CITAR ESTE ARTIGO:}

MENDES, Lucca Darwich; SANT'ANNA, Anderson de Souza; DINIZ, Daniela Martins. Liderança relacional e modernidade organizacional em firmas de advocacia. Revista Direito GV, São Paulo, v. 17, n. 3, set./dez. 2021, e2140. https://doi.org/10.1590/ 2317-6172202140

\section{Lucca Darwich Mendes}

Mestre em Administração pela Fundação Dom Cabral (FDC). SócIO-FUNDADOR E ADMINISTRADOR DA MENDES Advocacia E CONSUltoria. luccalamendesadv.com

\section{Anderson de Souza Sant'Anna}

Pós-doutor Pela Universidade Federal do Rio de Janeiro (UFRJ). DOUTOR EM AdMINISTRAÇÃO. DOUTOR EM ARQUITETURA E URbanismo pela Universidade Federal de Minas Gerais (UFMG). Professor da Escola de Administração de EMPRESAS de São Paulo da Fundação Getulio Vargas (FGV-EAESP). anderson.santannalafgv.br

\section{Daniela Martins Diniz}

Doutora em Administração pela Universidade Federal de Minas Gerais (UFMG). Professora da Universidade Federal DE SÃo JoÃo dEL REI (UFSJ). danidiniz09ayahoo.com.br 